\title{
Evaluation of antioxidant activity and total phenol in different varieties of Lantana camara leaves
}

\author{
Sanjiv Kumar, Rajat Sandhir and Sudarshan Ojha*
}

\begin{abstract}
Background: Phytochemicals like carotenoids, tocopherols, ascorbates and phenols present in the plants are strong antioxidants and have an important role in the health care system. There is growing interest in correlating the phytochemical constituents of a plant with its pharmacological activity. Therefore, the present study investigates the content of total phenolics, flavonoids and the antioxidant activity of four different varieties of Lantana camara L. (Verbenaceae) leaves by using in vitro antioxidant models.

Methods: The leaves of Chandigarh purple variety (CPV), Palampur red variety (PRV), Chandigarh yellow turning pink variety (YTPV) and Chandigarh yellow variety (CYV) Lantana camara were collected and the total phenolic, flavonoid content, antioxidant and free radical scavenging activities were determined in their methanolic extracts.

Results: The phenolic content was found to be highest in the CYV extract (232.99 $\pm 15.97 \mathrm{mg} \mathrm{GAE} / \mathrm{g}$ extract). The content of the flavonoids are in the order of YTPV, PRV, CPV and CYV. The IC $C_{50}$ values for the 2, 2-diphenyl-1picrylhydrazyl (DPPH) radical scavenging test were in the order of CYV $(33.30 \pm 2.39)<$ PRV $(40.32 \pm 2.94)<$ YTPV $(475.33 \pm 5.20)<$ CPV $(927.16 \pm 2.88 \mu \mathrm{g} / \mathrm{mL})$. The highest total antioxidant capacity was observed in CW $(222.20 \pm 5.05 \mathrm{mg}$ AAE/ g). The Ferric ion reducing antioxidant potential (FRAP) value of the extracts were in the order of CV > PRV > YTPV $>$ CPV. The IC $C_{50}$ values of 2, 2'-azino-bis-(3-ethylbenzothiazoline-6-sulfonate) (ABTS) scavenging assay for CY, PRV, YTPV, CPV were $18.25 \pm 0.19,18.24 \pm 1.82,50.43 \pm 9.49,52.84 \pm 1.82 \mu \mathrm{g} / \mathrm{mL}$ respectively. PRV extract showed the maximum in vitro lipid peroxidation inhibition effect with an $I_{50}$ value of $68.50 \mu \mathrm{g} / \mathrm{mL}$ which is even stronger as compared to the standard Rutin $(79.69 \mu \mathrm{g} / \mathrm{mL})$. The extracts showed a strong correlation between the phenolic content and their antioxidant activities. The highest correlation $\left(r=0.998, R^{2}=0.997\right)$ was found between total phenolic content and ABTS scavenging assay.
\end{abstract}

Conclusion: Among the four varieties investigated, CY and PRV extracts showed strong antioxidant activities and may be used as a potential source of natural antioxidant against free radical associated diseases.

Keywords: Lantana camara, Verbenaceae, Antioxidant activity, Total phenolic content, DPPH, ABTS

\section{Background}

Free radicals are fundamental to many biochemical processes and represent an essential part of aerobic life and metabolism. Reactive oxygen species (ROS) mediated oxidative damage to macromolecules namely lipids, proteins and DNA have been implicated in the pathogenicity of major diseases such as cancer, rheumatoid arthritis, post ischemic reperfusion injury, degeneration process of aging, myocardial infarction, cardiovascular disease etc. [1]. Antioxidants function through protection mechanisms

\footnotetext{
*Correspondence: s_ojha@pu.ac.in

Department of Biochemistry, BMS Block, Panjab University, Chandigarh 160014, India
}

(c) 2014 Kumar et al.; licensee BioMed Central Ltd. This is an Open Access article distributed under the terms of the Creative Commons Attribution License (http://creativecommons.org/licenses/by/4.0), which permits unrestricted use, distribution, and reproduction in any medium, provided the original work is properly credited. The Creative Commons Public Domain Dedication waiver (http://creativecommons.org/publicdomain/zero/1.0/) applies to the data made available in this article unless otherwise stated.

at several levels within cells in human body by inhibiting the formation of free radical species, intercepting radicalchained reactions, converting existing free radicals into less harmful molecules and repairing oxidative damage. Several synthetic antioxidants, such as butylated hydroxyanisol (BHA), butylated hydroxytoluene (BHT) and tert-butylhydroquinone (TBHQ) are commercially available but some adverse effects have been observed with their continuous use [2].

Fundamental biochemical processes of plants are considered to be the primary metabolic processes that generally follow similar mechanism in the cells of all plants and are necessary for each plant to survive and to reproduce. 
However, the plants produce a large number of compounds called secondary metabolites with diverse physiological and biochemical activities. Secondary metabolites and their derivatives show significant pharmacological activities such as being hepatoprotective, diuretic, anti allergic, anticancer effects and antioxidant [3-5]. Phytochemicals like carotenoids, tocopherols and tocotrienols, ascorbates and phenols are strong antioxidants and have carved out an important role in the health care system. There is renewed interest in finding out new natural antioxidants from living system for application in food, pharmaceutical and cosmetics.

Lantana camara $\mathrm{L}$. is regarded both as a notorious weed and a popular ornamental garden plant and has found various uses in folk medicine in many parts of the world [6]. Different parts of Lantana plant are considered antiseptic, antispasmodic, carminative and diaphoretic [7]. Anti-inflammatory, antipyretic and analgesic properties of extracts of $L$. camara leaves have also been reported [8]. Verbascoside isolated from the leaves of L. camara exhibited inhibition of protein kinase $C$ and antitumor activity [9].

The different varieties of $L$. camara have been reported to contain different types and levels of lantadenes and other phytochemicals [10], and may contain different bioactive constituents among these varieties of this Lantana species.

The present work aimed (i) to conduct a quantitative analyses of the antioxidant activity, total phenolic content and total flavonoids in methanolic extracts of different varieties of Lantana camara leaves (ii) to correlate the total phenolic content with the antioxidant activities as such comparative antioxidant study of these different varieties of $L$. camara has not been reported.

\section{Methods}

\section{Chemicals and reagents}

Gallic acid, 2,2-diphenyl-1-picrylhydrazyl (DPPH), 2, 4, 6-tripyridyl-s-triazine (TPTZ) and 2,2'-azino-bis-(3-ethylbenzothiazoline-6-sulfonate) (ABTS) were purchased from Sigma-Aldrich. Ascorbic acid, Folin-Ciocalteu's reagent, sodium carbonate and silica gel $\mathrm{F}_{254}$ TLC plates were from Merck (Mumbai, India). All the chemicals used including solvents were of analytical grade.

\section{Collection of plant material}

The leaves of different varieties were collected from different areas in and around Panjab University campus, Chandigarh and red variety was obtained from I.V.R.I. Palampur surroundings. The samples were authenticated and voucher specimens (Voucher specimen No. 20319 I-IV) deposited at the Herbarium, Department of Botany, Panjab University, Chandigarh. The leaves were washed, dried and grinded to make powders and then they were labelled and stored for further use. The different varieties of Lantana camara collected were Chandigarh purple variety (CPV), Palampur red variety (PRV), Chandigarh yellow turning pink variety (YTPV) and Chandigarh yellow variety (CYV).

\section{Methanolic extract preparation}

Lantana leaf powders were extracted with methanol $(10 \% \mathrm{w} / \mathrm{v})$ for 24 hours and filtered through four layers of muslin cloth and then through Whatman No. 1 filter paper. The extracts were then subjected to rotary vaporizer (Equitron, Roteva - $8763 \mathrm{RV}$ ) to evaporate methanol. The semi-solid residue obtained was blackish brown in color, henceforth called Lantana camara methanolic extract (LCME). The percentage yield (w/w) obtained for different varieties were CPV (14.22\%), PRV (16.82\%), YTPV (14.46\%) and CYV (15.72\%).

\section{Estimation of total phenolic content}

The total phenols were determined by method of McDonald et al., [11] with slight modifications. $10 \mathrm{mg}$ of gallic acid monohydrate was dissolved in $100 \mathrm{~mL}$ of methanol to give a concentration of $100 \mu \mathrm{g} / \mathrm{mL}$ and used as the standard. Different aliquots of 0.1 to $1.0 \mathrm{~mL}$ from the stock solution were taken in 10 graduated tubes. To each tube $2.5 \mathrm{~mL}$ of 1:1 mixture of Folin- Ciocalteu reagent and distilled water and $2 \mathrm{~mL}$ of $7.5 \%$ sodium carbonate were added. The mixture was allowed to stand for 30 minutes and the volume was made with water to get a concentration ranging from $1-10 \mu \mathrm{g} / \mathrm{mL}$. The absorbance of the resulting solutions was measured at $765 \mathrm{~nm}$ against reagent blank. A standard calibration curve was prepared by plotting absorbance against concentration and it was found to be linear over this concentration range. $10 \mathrm{mg}$ of extract was dissolved in $10 \mathrm{~mL}$ of methanol to get $1 \mathrm{mg} / \mathrm{mL}$ solution The concentration of total phenol in the test sample was determined from the calibration graph. The total phenol content in the extract was expressed in terms of gallic acid equivalent (mg GAE /g extract).

\section{Estimation of total flavonoid content}

Aluminium chloride colorimetric technique was used for flavonoids estimation [12]. $10 \mathrm{mg}$ of rutin was dissolved in $10 \mathrm{~mL}$ of methanol to get $1000 \mu \mathrm{g} / \mathrm{mL}$ solution and was used as standard. Aliquots ranging from 0.01 to $0.08 \mathrm{~mL}$ from the above stock solution were taken in different tubes. To each tube $1.5 \mathrm{~mL}$ of methanol, $0.1 \mathrm{~mL}$ of $10 \%$ aluminium chloride, $0.1 \mathrm{~mL}$ of $1 \mathrm{M}$ potassium acetate and $2.8 \mathrm{~mL}$ of distilled water was added. The reaction mixture was kept at room temperature for $30 \mathrm{~min}$. The absorbance of the resulting solutions was measured at $415 \mathrm{~nm}$ against reagent blank. The calibration curve was prepared by plotting absorbance against concentration and it was found to be linear over this 
concentration range. $10 \mathrm{mg}$ of extracts were dissolved in $10 \mathrm{~mL}$ of methanol to get $1 \mathrm{mg} / \mathrm{mL}$ solutions respectively. The concentration of total flavonoid in the test sample was determined from the calibration curve. The total flavonoid content in the extract was expressed as rutin equivalent (mg RE/g extract).

Thin layer chromatography analysis of antioxidant activity DPPH (2,2-Diphenyl-1-picrylhydrazyl) assay [13] was used as a rapid thin layer chromatography screening method to evaluate the antioxidant activity of the methanolic extracts due to free radical scavenging. DPPH is a purple coloured stable free radical, which on reduction gives yellow coloured diphenyl picryl hydrazine compound. $2.5 \mu \mathrm{L}$ of different methanolic extracts $(1 \mathrm{mg} / \mathrm{mL})$ were loaded on silica gel $\mathrm{F}_{254}$ TLC plates (Merck, Germany) which were sprayed with $0.05 \%$ DPPH solution in methanol and examined at 30 minutes after spraying. Any antioxidant compound is seen as a yellow spot on a purple background. Vitamin $\mathrm{C}$ and gallic acid were used as positive controls.

\section{DPPH radical scavenging activity}

The DPPH free radical scavenging activity of the extract, based on the scavenging of the stable 2, 2-diphenyl-1picrylhydrazyl (DPPH) free radical was determined [13]. It is a discoloration assay, which is evaluated by the addition of the antioxidant to a DPPH solution in methanol and the ability to scavenge the stable free radical of DPPH was measured in the absorbance at $517 \mathrm{~nm}$.

The solution of DPPH in methanol $(200 \mu \mathrm{M})$ was freshly prepared. Different concentrations of extracts were added to methanolic solution of DPPH. After $30 \mathrm{~min}$ at room temperature in dark, the absorbance was recorded at $517 \mathrm{~nm} . \mathrm{IC}_{50}$ value denotes the concentration of sample, which is required to scavenge $50 \%$ of DPPH free radicals. Radical scavenging activity was calculated by the following formula

$\%$ Radical Scavenging Activity $=\frac{\text { Absorbance }(\text { control })-\text { Absorbance }(\text { sample })}{\text { Absorbance }(\text { control })}$ $\times 100$

$\mathrm{IC}_{50}$ value was determined from the plotted graph of scavenging activity against the different concentrations of extracts, which is defined as the total antioxidant necessary to decrease the initial DPPH radical concentration by $50 \%$. The measurements were triplicated and their scavenging effects were calculated based on the percentage of DPPH scavenged.

\section{Evaluation of total antioxidant capacity}

The assay is based on the reduction of Mo (VI) to Mo (V) by the extract and subsequent formation of a green phosphate/Mo (V) complex at acidic $\mathrm{pH}$ [14]. $0.3 \mathrm{ml}$ extract was mixed with $3 \mathrm{ml}$ of reagent solution $(0.6 \mathrm{M}$ sulphuric acid, $28 \mathrm{mM}$ sodium phosphate and $4 \mathrm{mM}$ ammonium molybdate). The tubes containing the reaction solutions were incubated at $95^{\circ} \mathrm{C}$ for $90 \mathrm{~min}$. Then the absorbance of the solution was measured at $695 \mathrm{~nm}$ using a spectrophotometer against blank after cooling to room temperature. Methanol $(0.3 \mathrm{ml})$ in place of extract was used as blank. The antioxidant activity was expressed as ascorbic acid equivalent (mg AAE/g extract) which served as a positive control.

\section{Ferric ion reducing antioxidant potential (FRAP) assay}

A modified method of Benzie \& Strain [15] was adopted for the FRAP assay. The stock solutions prepared were $300 \mathrm{mM}$ acetate buffer (3.1 $\mathrm{g} \mathrm{CH}_{3} \mathrm{COONa}$ and $16 \mathrm{~mL}$ $\mathrm{CH}_{3} \mathrm{COOH}$ ), pH 3.6, 10 mM TPTZ (2, 4, 6-tripyridyl-striazine) solution in $40 \mathrm{mM} \mathrm{HCl}$, and $20 \mathrm{mM} \mathrm{FeCl}_{3}$ solution. The fresh working solution was prepared by mixing $25 \mathrm{~mL}$ acetate buffer, $2.5 \mathrm{~mL}$ TPTZ and $2.5 \mathrm{~mL}$ $\mathrm{FeCl}_{3}$ solution. The temperature of the solution was raised to $37^{\circ} \mathrm{C}$ before using. Different concentrations of plant extracts $(100 \mu \mathrm{L})$ were allowed to react with FRAP solution $(2900 \mu \mathrm{L})$ for $30 \mathrm{~min}$ in the dark condition. Readings of the coloured product (ferrous tripyridyltriazine complex) were taken at $593 \mathrm{~nm}$. The standard curve was linear between 200 to $1000 \mu \mathrm{M} \mathrm{FeSO}$. Results are expressed in $\mu \mathrm{M}$ Fe (II)/ g extract and compared with BHT as standard.

\section{ABTS radical scavenging assay}

The method of Re et al., [16] with slight modifications was adopted for ABTS (2,2' -azino-bis-(3-ethylbenzothiazoline6-sulfonate) assay. Briefly, a stock solution of ABTS radical cation was prepared by dissolving ABTS (7 mM) with potassium persulfate $\left(\mathrm{K}_{2} \mathrm{~S}_{2} \mathrm{O}_{8}, 2.45 \mathrm{mM}\right)$. The mixture was left to stand in the dark at room temperature for $16 \mathrm{~h}$ (the time required for formation of the radical) before use. For the evaluation of ABTS radical scavenging activity, the working solution was prepared by the previous solution and diluting it in ethanol to obtain the absorbance of $0.700 \pm 0.02$

Table 1 Total phenolic content (mg GAE /g extract) and flavonoid content (mg RE /g extract)

\begin{tabular}{ccc}
\hline Sample & $\begin{array}{c}\text { Total phenolic content } \\
(\mathbf{m g ~ G A E} / \mathbf{g}) \pm \mathbf{S D}\end{array}$ & $\begin{array}{c}\text { Flavonoid content } \\
(\mathbf{m g} \text { RE/ g) } \pm \text { SD }\end{array}$ \\
\hline CPV & $55.57 \pm 2.82^{\mathrm{b}}$ & $18.17 \pm 0.92^{\mathrm{b}}$ \\
PRV & $225.15 \pm 12.52^{\mathrm{a}}$ & $24.60 \pm 2.25^{\mathrm{a}}$ \\
YTPV & $70.91 \pm 4.57^{\mathrm{b}}$ & $25.22 \pm 2.59^{\mathrm{a}}$ \\
CYV & $232.99 \pm 15.97^{\mathrm{a}}$ & $16.14 \pm 0.21^{\mathrm{c}}$ \\
\hline
\end{tabular}

Results are expressed as mean $\pm \mathrm{SD}(\mathrm{n}=3)$. Gallic acid equivalent $(\mathrm{GAE})$ and rutin equivalent (R.E.).

Values in the column followed by a different letter superscript (a-c) are significantly different $(p<0.05)$ and values having same superscript are not statistically significant. 


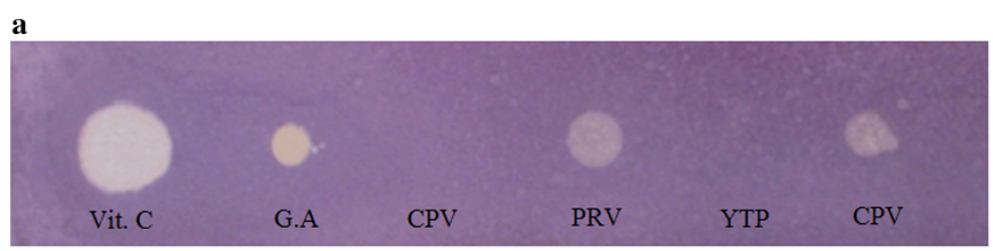

b

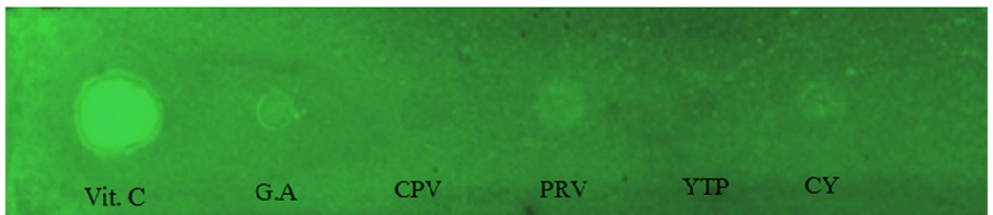

Figure 1 Antioxidant activity by qualitative DPPH test on $\mathbf{F}_{254}$ TLC plate (Merck). a) in visible light b) in U.V. light at $254 \mathrm{~nm}$. Vit. C (Vitamin C), G.A. (Gallic acid), CPV (Chandigarh Purple), PRV (Palampur red), YTPV (Yellow turning pink), CYV (Chandigarh yellow).

at $734 \mathrm{~nm}$. The solvent extracts $(0.1 \mathrm{~mL})$ at different concentrations were mixed with the ABTS working solution $(1.9 \mathrm{~mL})$ and the reaction mixture was allowed to stand at $30^{\circ} \mathrm{C}$ for $6 \mathrm{~min}$, then the absorbance was measured by using a UV-visible spectrophotometer at $734 \mathrm{~nm}$, at which point the antioxidants present in the extracts began to inhibit the radical, producing a reduction in absorbance, with a quantitative relationship between the reduction and the concentration of antioxidants present in the tested sample. The radical scavenging activities of the extracts were compared with that of BHT and percentage inhibition is calculated by equation:

$$
\text { ABTS radical scavenging effect }(\%)=\left[\left(\mathrm{A}_{\text {control }}-\mathrm{A}_{\text {sample }}\right) / \mathrm{A}_{\text {control }}\right]
$$

$$
\times 100
$$

\section{In vitro lipid peroxidation inhibition assay}

Rat liver was processed to get $10 \%$ homogenate in cold phosphate buffered saline, $\mathrm{pH} 7.4$ using polytron homogenizer and filtered to get a clear homogenate. The degree of lipid peroxidation was assayed by estimating the TBARS by using the method of Ohkawa et al., [17] with slight modifications. Different concentrations of the extracts $(20-100 \mu \mathrm{g} / \mathrm{mL})$ were added to liver homogenate. Lipid peroxidation was initiated by adding $50 \mu \mathrm{L}$ of
$15 \mathrm{mM}$ ferrous sulphate solution to $0.2 \mathrm{~mL}$ of homogenate. After $1 \mathrm{~h}, 1 \mathrm{~mL}$ of 15\% TCA followed by $1 \mathrm{~mL}$ of $0.67 \%$ TBA in $50 \%$ acetic acid was added to the tubes and heated in boiling water bath for $30 \mathrm{~min}$. The tubes were centrifuged and the intensity of the pink coloured complex was measured at $532 \mathrm{~nm}$. The control was prepared without fractions and rutin was used as the standard. The experimental procedure was approved by the Institutional animal ethics committee, Panjab University, Chandigarh. Experiments involving animals were conducted in accordance with the guidelines for the use of laboratory animals.

\section{Statistical analysis}

Assays were performed in triplicate and results are shown as mean \pm standard deviation. Linear regression analysis was used to calculate the $\mathrm{IC}_{50}$ values. Pearson's correlation coefficient was calculated using Microsoft excel 2007. Statistical significance was determined among various treatments with one way ANOVA test using SPSS 16.0 for Windows. A statistical significance of $\mathrm{p}<0.05$ was considered to be significant.

\section{Results and discussion}

Phenolic compounds are considered to be the most important antioxidants and are widely distributed among

\begin{tabular}{|c|c|c|c|}
\hline Sample & $\begin{array}{l}\text { DPPH radical scavenging } \\
\text { activity } I C_{50} \text { Value }(\mu \mathrm{g} / \mathrm{mL})\end{array}$ & $\begin{array}{c}\text { Total antioxidant } \\
\text { capacity }(\mathrm{mg} \text { AAE } / g) \pm S D\end{array}$ & $\begin{array}{c}\text { FRAP value } \\
(\mathrm{mM} \mathrm{Fe}(\mathrm{II}) / \mathrm{g}) \pm \mathrm{SD}\end{array}$ \\
\hline CPV & $927.16 \pm 2.88^{e}$ & $105.70 \pm 0.80^{d}$ & $5.60 \pm 0.25^{d}$ \\
\hline PRV & $40.32 \pm 2.94^{c}$ & $210.30 \pm 0.41^{b}$ & $236.30 \pm 6.11^{c}$ \\
\hline YTPV & $475.33 \pm 5.20^{d}$ & $155.40 \pm 2.72^{c}$ & $17.70 \pm 2.95^{d}$ \\
\hline CY & $33.30 \pm 2.39^{b}$ & $222.20 \pm 5.05^{a}$ & $339.00 \pm 11.13^{b}$ \\
\hline Vitamin C & $10.73 \pm 0.09^{a}$ & - & - \\
\hline $\mathrm{BHT}$ & - & - & $550.00 \pm 7.54^{\mathrm{a}}$ \\
\hline
\end{tabular}

Table 2 Effect of methanolic extracts of Lantana camara on different antioxidant models

Results are expressed as mean \pm SD $(n=3)$. Ascorbic acid equivalent (AAE). Values in the column followed by a different letter superscript (a-e) are significantly different $(p<0.05)$ and values having same superscript are not statistically significant. -, not determined. 


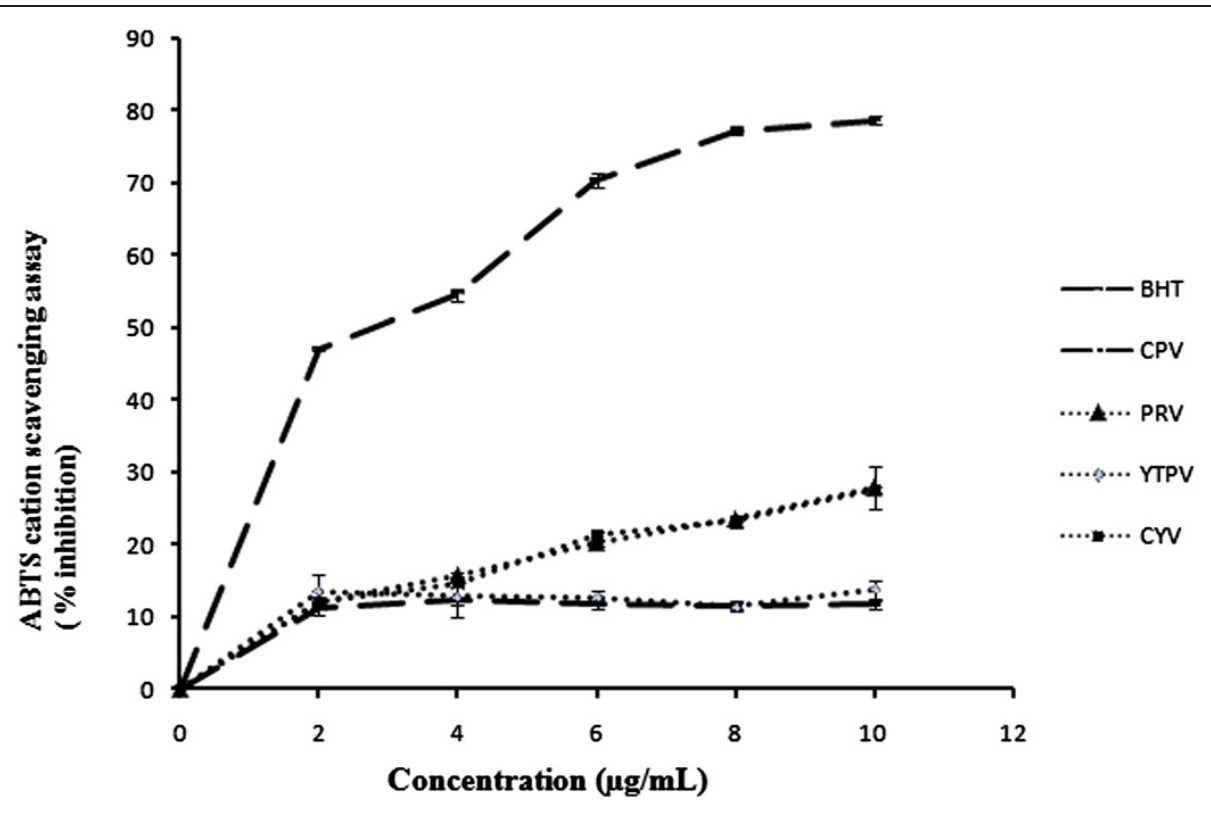

Figure 2 ABTS radical cation scavenging activity.

various plant species. These phenols play important roles in plants such as protection against herbivores and pathogens, cementing material joining phenolic polymers to cell wall polysaccharides [18], regulation of cell growth and cell division [19]. The phenolic content expressed as gallic acid equivalent per gram (GAE /g) in the CYV extract was found to be highest $(232.99 \pm 15.97 \mathrm{mg} \mathrm{GAE} / \mathrm{g})$ followed by PRV $(225.15 \pm 12.52 \mathrm{mg} \mathrm{GAE} / \mathrm{g})$, YTPV $(70.91 \pm 4.57 \mathrm{mg} \mathrm{GAE} / \mathrm{g})$ and CPV $(55.57 \pm 2.82 \mathrm{mg}$ GAE/g). Phenolic compounds exhibit their antioxidant activity by several mechanisms such as donating hydrogen atoms to free radicals, scavenging other reactive species such as $\mathrm{OH}^{*}, \mathrm{NO}_{2}^{*}, \mathrm{~N}_{2} \mathrm{O}_{3}, \mathrm{ONOOH}$ and $\mathrm{HOCl}$. Some phenolics, mostly the $\mathrm{di}$ and polyphenols, can react with $\mathrm{O}_{2}^{*}$ or by binding transition metal ions (especially iron and copper), often resulting in forms poorly active in promoting free radical reactions and hence can also interfere with the uptake of metals from the diet $[20,21]$. Phenolic acids such as caffeic acid and rosmarinic acid were reported to be among the abundant compounds in the methanolic extracts of aerial tissues of L. camara [22]. Vamanu and Nita showed that rosmarinic acid, a major phenolic compound, in the methanolic extracts of wild edible Boletus edulis mushroom is an effective antioxidant [23].

Flavonoids are water soluble polyphenolic compounds which are extremely common and wide spread in the plant kingdom as their glycosides. The contents of total flavonoid were measured by aluminium chloride method and are expressed in terms of rutin equivalent (RE) as $16.14 \pm 0.21 \mathrm{mg} \mathrm{RE} / \mathrm{g}$ for CYV, $18.17 \pm 0.92 \mathrm{mg} \mathrm{RE} / \mathrm{g}$ for $\mathrm{CPV}, 24.60 \pm 2.25 \mathrm{mg} \mathrm{RE} / \mathrm{g}$ for PRV, $25.22 \pm 2.59 \mathrm{mg} \mathrm{RE} / \mathrm{g}$ for YTPV (Table 1). The flavonoids act through scavenging or chelating process $[24,25]$. Ghisalberti mentioned six flavonoids, such as 3-methoxy-, 3, 7 dimethoxy- and 3, 7, 4'-trimethoxyquercetin, pectolinarigénin 7-O- $\beta$-D-glucoside, hispidulin and a camaraside glycoside in the leaves and stems of L. camara [7].

Table 3 Effect of methanolic extract of CPV, PRV, YTPV and CYV compared with BHT as standard on ABTS radical scavenging assay

\begin{tabular}{|c|c|c|c|c|c|}
\hline \multirow[t]{2}{*}{ Conc. $(\mu \mathrm{g} / \mathrm{mL})$} & \multicolumn{5}{|c|}{$\left[\mathrm{IC}_{50}\right.$ values are mean $\pm \mathrm{SD}$ of 3 replicates] Inhibition (\%) } \\
\hline & BHT & CPV & PRV & YTPV & CYV \\
\hline 2 & $47.15 \pm 0.32$ & $11.13 \pm 0.45$ & $12.05 \pm 0.31$ & $13.60 \pm 2.32$ & $12.10 \pm 0.73$ \\
\hline 4 & $54.61 \pm 0.85$ & $12.29 \pm 0.59$ & $15.74 \pm 0.58$ & $12.82 \pm 2.84$ & $14.67 \pm 0.59$ \\
\hline 6 & $70.55 \pm 0.95$ & $11.66 \pm 0.39$ & $20.26 \pm 0.38$ & $12.68 \pm 0.91$ & $21.28 \pm 0.52$ \\
\hline 8 & $77.30 \pm 0.51$ & $11.56 \pm 0.17$ & $23.47 \pm 0.25$ & $11.51 \pm 0.52$ & $23.17 \pm 0.77$ \\
\hline 10 & $78.71 \pm 0.53$ & $11.66 \pm 0.25$ & $27.78 \pm 2.92$ & $13.79 \pm 1.38$ & $27.50 \pm 0.44$ \\
\hline $\mathrm{IC}_{50}(\mu \mathrm{g} / \mathrm{mL})$ & $4.34 \pm 0.03^{a}$ & $52.84 \pm 1.82^{c}$ & $18.24 \pm 1.17^{b}$ & $50.43 \pm 9.49^{c}$ & $18.25 \pm 0.19^{b}$ \\
\hline
\end{tabular}

Values in the row followed by a different letter superscript $(a-c)$ are significantly different $(p<0.05)$ and values having same superscript are not statistically significant. 


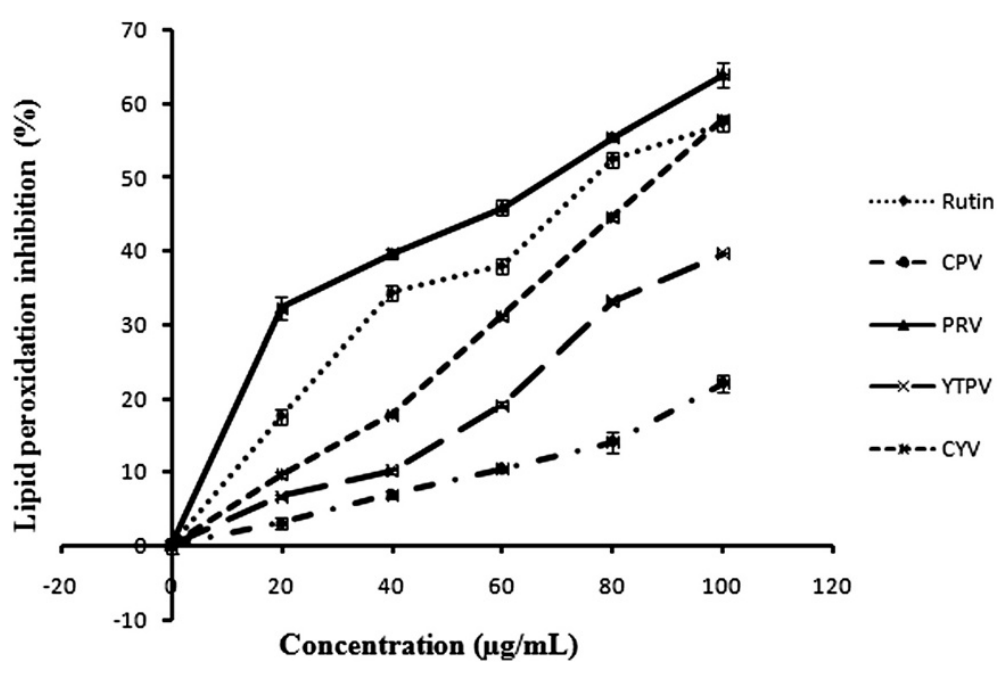

Figure 3 In vitro lipid peroxidation inhibition activity.

The result of the qualitative DPPH test on TLC plate $\left(\mathrm{F}_{254}\right)$ is shown in Figure 1. The DPPH scavenging effects are expressed as yellow zones of the various extracts on the purple background as compared to positive controls ascorbic acid (Vitamin C) and gallic acid and blank TLC plate as negative control.

Table 2 shows the $\mathrm{IC}_{50}$ values of leaf extracts for DPPH free radical scavenging activity for CYV $(33.30 \pm$ $2.39 \mu \mathrm{g} / \mathrm{mL})$, PRV $(40.32 \pm 2.94 \mu \mathrm{g} / \mathrm{mL})$, YTPV $(475.33 \pm$ $5.20 \mu \mathrm{g} / \mathrm{mL}), \mathrm{CPV}(927.16 \pm 2.88 \mu \mathrm{g} / \mathrm{mL})$. The lower $\mathrm{IC}_{50}$ value indicates higher antioxidant capacity and hence CYV extract showed significantly higher radical scavenging activity as compared to PRV, YTPV and CPV. The radical scavenging activity is in accordance with the levels of phenolic content in the extracts respectively. Free radical scavenging activity of extracts of black chokeberry and blueberry has been reported to be correlated with its total phenolics content [26].

Total antioxidant capacity is a better way of depiction of combined effect of phenolics, flavonoids and other reducing compounds in the plant extracts and is expressed in terms of ascorbic acid equivalents (AAE).
The phosphomolybdenum method is based on the reduction of Mo (VI) to Mo (V) by the action of antioxidant compounds and the formation of a green phosphate - Mo (V) complex with a maximal absorption at $695 \mathrm{~nm}$. A significantly higher total antioxidant capacity was observed in CYV (222.20 $\pm 5.05 \mathrm{mg} \mathrm{AAE} / \mathrm{g})$ followed by PRV $(210.30 \pm 0.41 \mathrm{mg}$ AAE/ g), YTPV $(155.40 \pm 2.72 \mathrm{mg}$ $\mathrm{AAE} / \mathrm{g})$ and CPV $(105.70 \pm 0.80 \mathrm{mg} \mathrm{AAE} / \mathrm{g})$ (Table 2). The total antioxidant capacity values follow the same order as that of phenolic content in the extracts respectively.

The ferric ion reducing antioxidant potential (FRAP) of different extracts were estimated from their ability to reduce TPTZ-Fe (III) to TPTZ-Fe (II). The FRAP value of the extracts is in the order of BHT $(550.00 \pm 7.54 \mathrm{mM}$ $\mathrm{Fe} \quad(\mathrm{II}) / \mathrm{g})>\mathrm{CYV} \quad(339.00 \pm 11.13 \mathrm{mM}$ Fe $(\mathrm{II}) / \mathrm{g})>\mathrm{PRV}$ $(236.30 \pm 6.11 \mathrm{mM} \mathrm{Fe}(\mathrm{II}) / \mathrm{g})$, YTPV $(17.70 \pm 2.95 \mathrm{mM} \mathrm{Fe}$ (II)/g) followed by CPV $(5.60 \pm 0.25 \mathrm{mM} \mathrm{Fe}$ (II)/g) (Table 2). The differences in the values are found to be significant and are in order with their phenolic content.

Protonated radical scavenging is an important attribute of antioxidants. ABTS, a protonated radical, has characteristic absorbance maxima at $734 \mathrm{~nm}$ which decreases

Table 4 Effect of methanolic extract of CPV, PRV, YTPV and CYV compared with Rutin as standard on in vitro lipid peroxidation inhibition assay in rat liver

\begin{tabular}{|c|c|c|c|c|c|}
\hline \multirow[t]{2}{*}{ Conc. $(\mu \mathrm{g} / \mathrm{mL})$} & \multicolumn{5}{|c|}{$\left[{ }^{\prime} C_{50}\right.$ values are mean $\pm S D$ of 3 replicates] Inhibition (\%) } \\
\hline & Rutin & CPV & PRV & YTPV & CYV \\
\hline 20 & $17.62 \pm 1.05$ & $3.09 \pm 0.67$ & $32.24 \pm 1.56$ & $6.76 \pm 0.27$ & $9.66 \pm 0.45$ \\
\hline 40 & $34.33 \pm 1.00$ & $6.99 \pm 0.51$ & $39.67 \pm 0.59$ & $10.19 \pm 0.34$ & $17.8 \pm 0.26$ \\
\hline 60 & $38.00 \pm 1.00$ & $10.43 \pm 0.38$ & $45.91 \pm 1.00$ & $19.18 \pm 0.44$ & $31.14 \pm 0.36$ \\
\hline 80 & $52.47 \pm 0.91$ & $14.14 \pm 1.40$ & $55.48 \pm 0.50$ & $33.23 \pm 0.35$ & $44.62 \pm 0.45$ \\
\hline 100 & $57.24 \pm 1.03$ & $22.14 \pm 1.17$ & $63.95 \pm 1.69$ & $39.76 \pm 0.09$ & $57.86 \pm 0.35$ \\
\hline IC ${ }_{50}(\mu \mathrm{g} / \mathrm{mL})$ & $79.68 \pm 0.66^{b}$ & $242.78 \pm 6.96^{\mathrm{e}}$ & $68.51 \pm 0.48^{a}$ & $127.58 \pm 3.03^{d}$ & $89.77 \pm 0.72^{\circ}$ \\
\hline
\end{tabular}

Values in the row followed by a different letter superscript $(a-e)$ are significantly different $(p<0.05)$ and values having same superscript are not statistically significant. 


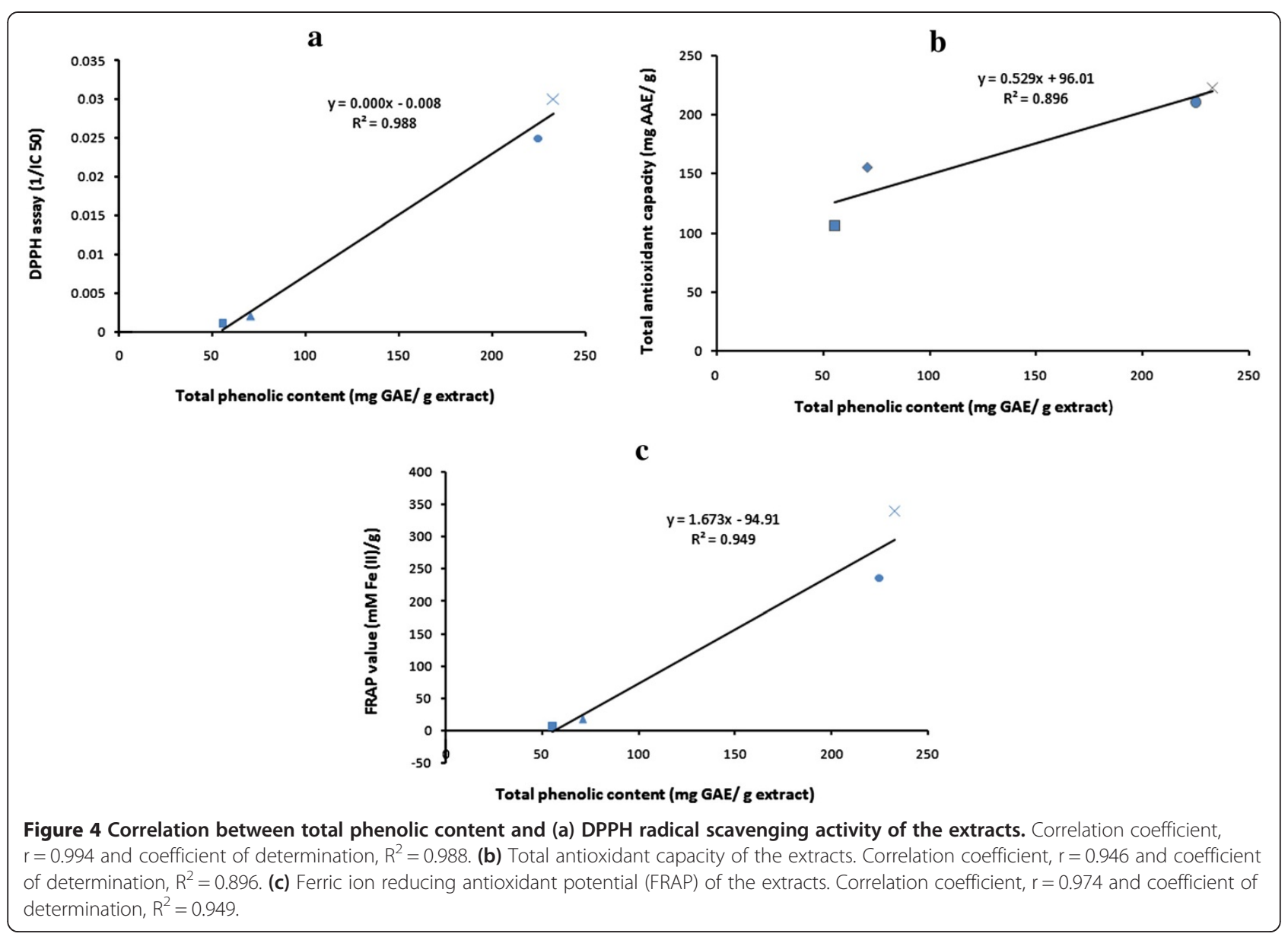

with the scavenging of the proton radicals [27]. The extracts were fast and effective scavengers of the ABTS cation radical (Figure 2). The $\mathrm{IC}_{50}$ values for PRV $(18.24 \pm 1.82 \mu \mathrm{g} / \mathrm{mL})$, CYV $(18.25 \pm 0.19 \mu \mathrm{g} / \mathrm{mL})$, YTPV $(50.43 \pm 9.49 \mu \mathrm{g} / \mathrm{mL})$ and CPV $(52.84 \pm 1.82 \mu \mathrm{g} / \mathrm{mL})$ are given in Table 3.
Lipid peroxidation is the oxidative degradation of polyunsaturated fatty acids and involves the formation of lipid radicals leading to membrane damage. Free radicals induce lipid peroxidation in polyunsaturated lipid rich areas like brain and liver [28] and can also damage DNA, proteins and other biological molecules. Initiation of $\mathbf{a}$

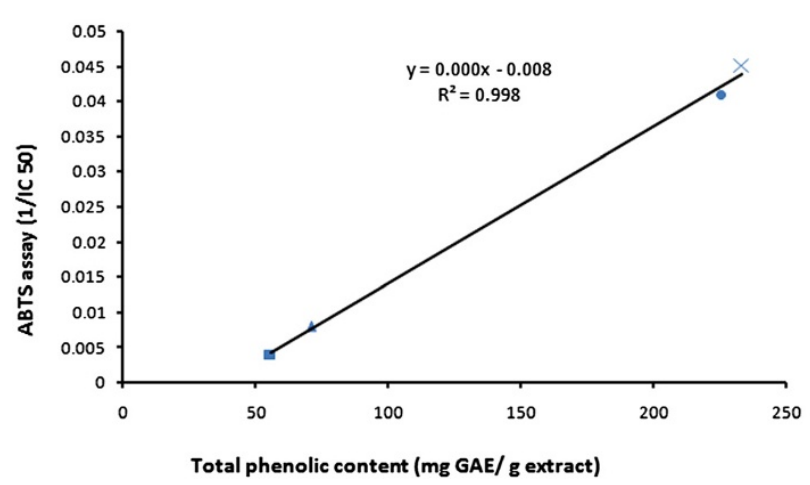

b

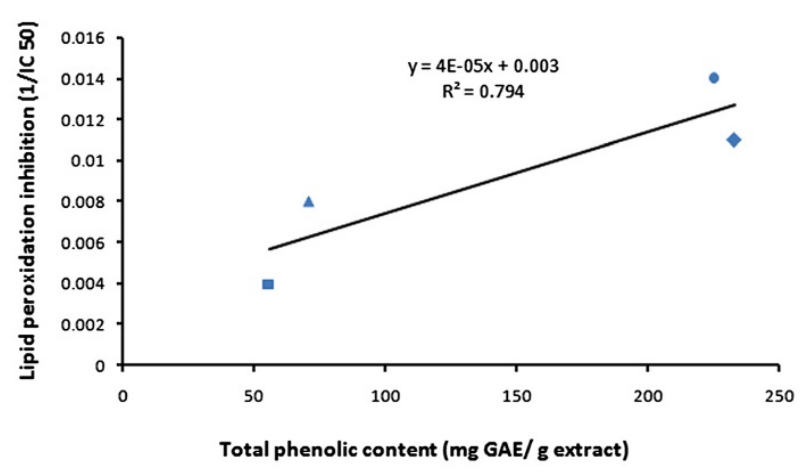

Figure 5 Correlation between total phenolic content and (a) ABTS scavenging activity of the extracts. Correlation coefficient, $r=0.998$ and coefficient of determination, $R^{2}=0.997$ (b) Lipid peroxidation inhibition activity of the extracts. Correlation coefficient, $r=0.891$ and coefficient of determination, $R^{2}=0.794$. 
lipid peroxidation by ferrous sulphate takes place either through ferryl-perferryl complex [29] or through hydroxyl radical by Fenton reaction [30] depending upon the reaction conditions. The extracts showed the in vitro lipid peroxidation inhibition effects in a concentration dependent manner and the results are expressed in terms of percentage inhibition (Figure 3 ) and $\mathrm{IC}_{50}$ values for the same are calculated from the regression equation respectively (Table 4). PRV extract showed the significantly maximum inhibitory effect with lowest $\mathrm{IC}_{50}$ value of $68.51 \pm 0.48 \mu \mathrm{g} / \mathrm{mL}, \mathrm{CYV}(89.77 \pm 0.72 \mu \mathrm{g} / \mathrm{mL})$, YTPV $(127.59 \pm 3.03 \mu \mathrm{g} / \mathrm{mL}), \mathrm{CPV}(242.78 \pm 6.96 \mu \mathrm{g} / \mathrm{mL})$ as compared to the standard rutin which was showing the inhibitory effect with an $\mathrm{IC}_{50}$ value of $79.68 \pm 0.66 \mu \mathrm{g} / \mathrm{mL}$. Here, PRV showed higher inhibitory effect than rutin $(1 \mathrm{mg} / \mathrm{mL})$ used as a standard. Lipid peroxidation inhibiting activity of Lantana extracts may be due to the compounds such as rosmarinic acid, caffeic acid etc. Caffeic acid (3,4-dihydroxycinnamic acid) has been shown to prevent the lipid peroxidation of food induced by the free radicals and also in pathological conditions, such as cancer and ageing [31]. Aqueous extract of Lantana camara has been reported to inhibit pBR322 plasmid DNA damage induced by free radicals [32] indicating the presence of compounds with strong antioxidant properties.

The correlation of total phenolic content with $\mathrm{DPPH}$, FRAP and ABTS scavenging activities are shown in Figure 4 (a), (b) and (c) respectively. The Pearson's correlation coefficient $(r)$ and coefficient of determination $\left(R^{2}\right)$ was highest $\left(r=0.998, R^{2}=0.997\right)$ between total phenolic content and ABTS activity than that of total phenolic content and DPPH activity $\left(r=0.994, R^{2}=0.988\right)$ followed by total phenolic content and FRAP activity $\left(r=0.974, \mathrm{R}^{2}=0.949\right)$.

The correlation between total phenolic content with total antioxidant capacity and in vitro lipid peroxidation inhibition activity is shown in Figure 5 (a) and (b) respectively. A correlation $\left(r=0.946, R^{2}=0.833\right)$ was observed in Figure 5 (a) and a relatively lower correlation $(\mathrm{r}=0.891$, $\mathrm{R}^{2}=0.794$ ) in case of Figure $5(\mathrm{~b})$. Reports have suggested that there is a correlation between the total phenolic content and antioxidant activity of plant extracts [33]. However, no correlation is found between the flavonoid content and the antioxidant activities of the extracts in the present study.

The high correlations confirm the role of phenolic compounds as the main contributor to the antioxidant activities of the Lantana camara leaf extracts. The types and quantities of phenolic compounds might contribute to the varying antioxidant activity of extracts from different varieties. Some phenolic compounds such as salicylic acid, gentisic acid, $\beta$-resorcylic acid, coumarin, ferulic acid and 6-Methyl coumarin were identified in L. camara extract [34].

\section{Conclusion}

On the basis of the results obtained in the present study, it is concluded that the methanolic leaf extracts of four different varieties of Lantana camara which contains large amount of phenolic compounds, exhibit high antioxidant, free radical scavenging and in vitro lipid peroxidation inhibition activities. A high correlation is found between the total phenolic content and the antioxidant activities using different in vitro antioxidant models in this study. These in vitro assays indicate that these four different varieties has a varying antioxidant activity, and thereby indicate that among them CYV and PRV varieties are good source of antioxidants, which might be useful in preventing the progress of various oxidative conditions. Hence, more queries will be addressed in future studies targeting these varieties to explore the potential and isolation of bioactive compounds responsible for such activities and as chemo preventive and therapeutic agents.

\section{Abbreviations}

AAE: Ascorbic acid equivalent; RE: Rutin equivalent; GAE: Gallic acid equivalent; TLC: Thin layer chromatography; DPPH: 2,2-diphenyl-1-picrylhydrazyl; FRAP: Ferric ion reducing antioxidant potential; ABTS: 2,2'-azino-bis-(3-ethylbenzothiazoline-6sulfonate); ROS: Reactive oxygen species; CPV: Chandigarh purple variety; PRV: Palampur red variety; YTPV: Yellow turning pink variety; CY: Chandigarh yellow variety.

\section{Competing interests}

The authors declare that they have no competing interests.

\section{Authors' contributions}

SO and RS: Designed the study. SK: Carried out the tests and prepared the manuscript. All the authors read and approved the final manuscript.

\section{Acknowledgments}

Authors would like to thank CSIR, New Delhi for providing financial support and fellowship to Sanjiv Kumar.

Received: 3 May 2014 Accepted: 18 August 2014

Published: 22 August 2014

\section{References}

1. Mohammad A: Oxidative stress and experimental carcinogenesis. Ind J Exp Biol 2002, 40:656-667.

2. Wichi HP: Enhanced tumor development of butylated hydroxyanisol (BHA) from the prospective of effect on fore stomach and oesophageal squamous epithelium. Food Chem Toxicol 1998, 26:717-723.

3. Williams RJ, Spenser JPE, Rice-Evans C: Flavonoids: antioxidants or signalling molecules? Free Radic Biol Med 2004, 36:838-849.

4. Mulubagal $\mathrm{V}$, Tsay $\mathrm{H}$ : Plant cell cultures - an alternative and efficient source for the production of biologically important secondary metabolites. Int J App/ Sci Eng Tech 2004, 2:29-48.

5. Borneo R, Leon EA, Aguirre A, Ribotta P, Cantero JJ: Antioxidant capacity of medicinal plants from the Province of Cordoba (Argentina) and their in vitro testing in model food system. Food Chem 2008, 112:664-670.

6. Ghisalberti EL: Review Lantana camara L. (Verbenaceae). Fitoterapia 2000, 71:467-486

7. Parrotta JA: Healing Plants of Peninsular India. New York: CAB International; 2001:710-711.

8. Forestieri AM, Monforte MT, Ragusa S, Trovato A, lauk L: Anti-inflammatory, analgesic and antipyretic activity in rodents of plant extracts used in African medicine. Phytother Res 1996, 10:100-106.

9. Herbert JM, Maffrand JP, Taoubi K, Augereau JM, Fouraste I, Gleye J: Verbascoside isolated from Lantana camara, an inhibitor of protein kinase C. J Nat Prod 1991, 54:1595-1600. 
10. Sharma OP, Jagdish V, Sharma PD: Comparison of lantadenes content and toxicity of different variety of the lantana plant. J Chem Ecol 1991, 17(11):2283-2291.

11. McDonald S, Prenzler PD, Autolovich M, Robards K: Phenolic content and antioxidant activity of olive extracts. Food Chem 2001, 73:73-84.

12. Chang $C$, Yang $M$, Wen $H$, Chern J: Estimation of total flavonoid content in propolis by two complementary colorimetric methods. J Food Drug Anal 2002, 10:178-182

13. Blois MS: Antioxidant determinations by the use of a stable free radical. Nature 1958, 181(4617):1199-1200.

14. Prieto $P$, Pineda $M$, Aguilar M: Spectrophotometric quantitation of antioxidant capacity through the formation of phosphomolybdenum complex: specific application to determination of vitamin E. Anal Biochem 1999, 269:337-341.

15. Benzie IEF, Strain JJ: The ferric reducing ability of plasma (FRAP) as a measure of "antioxidant power". The FRAP assay. Anal Biochem 1996, 239:70-76.

16. Re R, Pellegrini N, Proteggente A, Pannala A, Yang M, Rice-Evans C: Antioxidant activity applying an improved $A B T S$ radical cation decolorization assay. Free Radic Biol Med 1999, 26:1231-1237.

17. Ohkawa H, Ohishi N, Yagi K: Assay for lipid peroxides in animal tissues by thiobarbituric acid reaction. Anal Biochem 1979, 95:351-358.

18. Wallace G, Fry SC: Phenolic compounds of the plant cell. International Review of CYVology 1994, 151:229-267.

19. Binns AN, Chen RH, Wood HN, Lynn DG: Cell division promotion activity of naturally occurring dehydrodiconiferyl glucosides: Do cell wall components control cell division? Proc Natl Acad Sci U S A 1987, 84:980-984

20. Zin ZM, Hamid AA, Osman A, Saari N: Antioxidative activities of chromatographic fractions obtained from root, fruit and leaf of Mengkudu (Morinda citrifolia L.). Food Chem 2006, 94:169-178.

21. Taubert D, Breitenbach T, Lazar A, Censarek P, Harlfinger S, Berkels R, Klaus $W$, Roesen $\mathrm{R}$ : Reaction rate constant of $\mathrm{O}_{2}^{-}$scavenging by plant antioxidants. Free Rad Biol Med 2003, 35:1599.

22. Bangou MJ, Almaraz-Abarca N, Méda NTR, Zeba B, Kiendrebéogo M, Millogo-Rasolodimby J, Nacoulma OG: Polyphenolic composition of Lantana camara and Lippia chevalieri, and their antioxidant and antimicrobial activities. International Journal of Phytomedicine 2012, 4:115-124.

23. Vamanu E, Nita S: Antioxidant capacity and the correlation with major phenolic compounds, anthocyanin, and tocopherol content in various extracts from the wild edible Boletus edulis mushroom. BioMed Research International 2013, 2013:313905.

24. Kessler M, Ubeaud G, Jung L: Anti- and pro-oxidant activity of rutin and quercetin derivatives. J Pharm Pharmacol 2003, 55:131-142.

25. Cook NC, Samman S: Flavonoids- chemistry, metabolism, cardioprotective effects, and dietary sources. Nutr Biochem 1996, 7:66-76

26. Hwang SJ, Yoon WB, Lee OH, Cha SJ, Kim JD: Radical-scavenging-linked antioxidant activities of extracts from black chokeberry and blueberry cultivated in Korea. Food Chem 2014, 146:71-77.

27. Mathew S, Abraham TE: In vitro antioxidant activity and scavenging effects of Cinnamomum verum leaf extract assayed by different methodologies. Food Chemistry and Toxicology 2006, 44:198-206.

28. Coyle JT, Puttfarcken P: Oxidative stress, gluatamate and neurodegenerative diseases. Science 1993, 219:1184.

29. Gutteridge JMC: Age, pigments and free radicals: fluorescent lipid complexes by iron and copper containing proteins. Biochim Biophys Acta 1985, 834:144

30. Halliwell B: Superoxide dependent formation of hydroxyl free radicals in the presence of iron chelates. FEBS Lett 1978, 92:321.

31. Gulcin I: Antioxidant activity of caffeic acid (3,4-dihydroxycinnamic acid). Toxicology 2006, 217:213-220

32. Kalita S, Kumar G, Karthik L, Rao KVB: In vitro antioxidant and DNA damage inhibition activity of aqueous extract of Lantana camara $\mathrm{L}$. (Verbenaceae) leaves. Asian Pac J Trop Biomed 2012, 2(3):S1675-S1679.
33. Zhang $Y$, Wang Z: Phenolic composition and antioxidant activities of two Plomis species: a correlation study. CR Biologies 2009, 332:816-826.

34. Yi Z, Zhang M, Ling B, Xu D, Ye J: Inhibitory effects of Lantana camara and phenolic compounds from it on growth of Eichhornia crassipes. Yingyong Shengtai Xuebao 2006, 17:1637-1640.

doi:10.1186/1756-0500-7-560

Cite this article as: Kumar et al:: Evaluation of antioxidant activity and total phenol in different varieties of Lantana camara leaves. BMC

Research Notes 2014 7:560.

\section{Submit your next manuscript to BioMed Central and take full advantage of:}

- Convenient online submission

- Thorough peer review

- No space constraints or color figure charges

- Immediate publication on acceptance

- Inclusion in PubMed, CAS, Scopus and Google Scholar

- Research which is freely available for redistribution

Submit your manuscript at www.biomedcentral.com/submit
C) Biomed Central 